\title{
La manifestación salvífica de Dios y su discernimiento en los signos de los tiempos. \\ El giro soteriológico-pastoral en el Concilio Vaticano II
}

\author{
Virginia R. Azcuy \\ FACULTAD DE TEOLOGÍA \\ PONTIFICIA UNIVERSIDAD CATÓLICA DE CHILE \\ vrazcuy@yahoo.com.ar
}

Resumen: Este estudio reelabora una presentación en el Seminario Interno de Profesores de la Facultad de Teología de la Universidad Católica realizado en 2013, dedicado al giro soteriológico en la comprensión de la fe según el Concilio Vaticano II. La exposición se desarrolla en dos unidades relacionadas: primero, una exégesis de dos textos conciliares que ayuda a profundizar el tema de la acción trinitaria salvífica en la historia de la humanidad y su discernimiento creyente: LG 5 y GS 44. Segundo, un ensayo sistemático a partir del concepto signa temporum, que tanto interesa a la hora de descubrir la manifestación de Dios en la historia, seguido de una formulación sintética sobre algunos desafíos teológicos para su interpretación. A modo de conclusión, se enuncian algunas cuestiones abiertas sobre el giro soteriológico-pastoral del Vaticano II.

Palabras clave: Vaticano II, signos de los tiempos, salvación, giro pastoral.

Abstract: This study is based on a presentation in 2013 in a Seminary for Teachers of the Faculty of Theology of the Catholic University of Argentina. It was dedicated to the soteriological shift in the understanding of faith according to Vatican II. The paper is organized in two related units: first, an exegesis of two conciliar texts that give further insight to the theme of Trinitarian salvation in the history of humanity and Christian discernment: LG 5 and GS 44. Second, a systematic essay based on the concept signa temporum, of great interest at the time of discovering the manifestation of God in history, followed by a synthetic formulation on some theological challenges for interpretation. The conclusion enounces, some open questions about the soteriological and pastoral turn made by Vatican II.

Keywords: Vatican II, signa temporum, salvation, pastoral turn. 
La eclesiología del Concilio Vaticano II se presenta en el marco del dinamismo salvífico que dimana de la Trinidad en la historia: "toda la doctrina conciliar ha quedado situada en esta clave trinitario-económica" ${ }^{1}$. El concepto eclesiológico de mysterion (misterio) y el correspondiente a su traducción latina sacramentum (sacramento), presentes al comienzo de la Constitución Dogmática sobre la Iglesia Lumen Gentium van en este sentido $^{2}$. De modo semejante juega el adjetivo pastoral, aplicado a este Concilio y sobre todo a la Constitución Gaudium et spes sobre la presencia de la Iglesia en el mundo actual ${ }^{3}$. En este marco, las dimensiones ad intra y ad extra que fueron programáticas para el desarrollo de la eclesiología en las sesiones conciliares, representan -sobre todo el ad extra- una expresión característica de la pastoralidad del Concilio ${ }^{4}$. En definitiva, que la Iglesia sea "sacramento universal de salvación" en la historia, expresa su función de medio o servicio para alcanzar la salvación de Dios a la humanidad (cf. LG 48b; GS 45a; AG 1a). Y en definitiva, el giro conciliar en la comprensión de la Iglesia, significa el paso de una visión eclesiocéntrica y separada del mundo hacia otra mistérica, de instrumento unido al Espíritu para la salvación de la humanidad (cf. LG 8a)

Esta Iglesia sacramento, inaugurada en Cristo y animada por su Espíritu, prolonga en la historia las misiones trinitarias del Hijo y el Espíritu, como las dos manos de Dios Padre que se acercan a la humanidad -para decirlo con la hermosa imagen de los padres de la Iglesia-. En la historia,

1 N. Silanes, "La Iglesia de la Trinidad". La Santísima Trinidad en el Vaticano II. Estudio genético-teológico (Secretariado Trinitario, Salamanca 1981) 101.

2 Cf. G. PHilips, La Iglesia y su misterio en el Concilio Vaticano II. Historia, texto y comentarios de la constitución "Lumen Gentium"(Herder, Barcelona 1968, t.1) 91-97.

3 Cf. C. Schickendantz, "Una elipse con dos focos: hacia un nuevo método teológico a partir de Gaudium et spes", en V. R. Azcuy; C. SchickendanTz; E. Silva (eds.), Teología de los signos de los tiempos latinoamericanos. Horizontes, criterios y métodos (Ediciones Universidad Alberto Hurtado, Santiago de Chile 2013) 53-87, 59ss.

4 Estas dos dimensiones, ya presentes en el famoso Radiomensaje de Juan XXIII del 11 de septiembre de 1962 (AAS LIV [1962] 678-685), fueron propuestas por el Card. Suenens el 4 de diciembre siguiente como "plan de conjunto" para las sesiones conciliares. Cf. Acta Synodalia Sacrosancti Concilii Vaticani II, I/IV, 222-227, 223.

5 Para un desarrollo histórico de la dimensión sacramental y mistérica de la Iglesia, cf. S. PiÉ-Ninot, Eclesiología. La sacramentalidad de la comunidad cristiana (Sígueme, Salamanca 2007) 51-74. 
Cristo manifiesta la salvación en su persona, sus palabras y sus gestos; quien da ojos para percibir su figura y oídos para distinguir su palabra es su Espíritu ${ }^{6}$. La Iglesia del Vaticano II, enraizada en el misterio de salvación, se desenvuelve en tensión misionera o ad extra en la historia y reconoce también en esta el lugar de la manifestación del reino (cf. GS 39). Es en este horizonte que se ha de entender la exhortación de "escrutar y discernir los signos de los tiempos" (GS 4), es decir, la invitación a reconocer la oferta y el llamado de salvación en los tiempos históricos, los signos de Dios en los acontecimientos y las aspiraciones del presente (cf. 11). La "topología plural de los signos" -en la expresión de H. J. Sander7- desafía a la Iglesia a un discernimiento permanente de la historia, que no puede darse -según lo entiende Y. Congar- sin la actitud de querer aprender de la historia ${ }^{8}$. Se trata de un giro realmente saludable y plenamente actual en el contexto latinoamericano, como queda expresado en la V Conferencia de Aparecida que propone "asumir una actitud de permanente conversión pastoral, que implica escuchar con atención y discernir «lo que el Espíritu está diciendo a las iglesias» (Ap 2, 29) a través de los signos de los tiem-

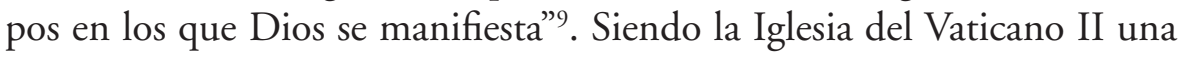
Ecclesia semper reformanda ${ }^{10}$, ella se esfuerza por "prestar oídos a la Palabra definitiva de Dios en Jesucristo, (y al hacerlo) los cristianos se abren a la escucha de los ecos de su voz en las otras personas, lugares y culturas (cf. Hch 14, 15-17; 17, 24-28; Rom 1, 19-30)"11.

El presente estudio retoma, con algunas adaptaciones, una presentación en el Seminario Interno de Profesores de la Facultad de Teología de

6 Cf. H. U. von Balthasar, “El Desconocido más allá del Verbo”, en Ensayos Teológicos III. Spiritus Creator (Encuentro, Madrid 2004) 89-98, 94.

7 Cf. H. J. SANDER, "Die singuläre Geschichtshandeln Gottes - eine Frage der pluralen Topologie der Zeichen der Zeit”, en P. Hünermann; B. J. Hilberath (eds.), Herders Theologischer Kommentar zum Zweiten Vatikanischen Konzil (Herder, Freiburg/Basel/Wien 2006, t.5) 134-147, 142.

8 Cf. Y. Congar, "El Esquema XIII”, en Diario del Concilio. Tercera Sesión (Estella, Barcelona, 1965) 75-83, 76. Texto citado por C. Schickendantz, "Una elipse con dos focos..." 71.

9 V Conferencia General del Episcopado Latinoamericano y del Caribe, Aparecida. Documento Conclusivo (Conferencia Episcopal Argentina, Buenos Aires, 2007) № 366.

10 La expresión de LG 8c, que reemplaza a la fórmula "Iglesia pecadora", quiere destacar la condición histórica e inacabada de la Iglesia peregrina. Cf. A. AnTón, La Iglesia de Cristo. El Israel de la Vieja y de la Nueva Alianza (BAC, Madrid 1977) 778.

11 Comisión Teológica Internacional, La teología hoy: perspectivas, principios y criterios (BAC, Madrid 2012) N 57. 
la Universidad Católica, realizado en 2013, sobre el giro soteriológico en la comprensión de la fe según el Concilio Vaticano II $^{12}$. La exposición se desarrolla en dos unidades relacionadas: primero, una exégesis de dos textos conciliares que ayuda a profundizar el tema de la acción trinitaria salvífica en la historia de la humanidad y su discernimiento creyente: LG 5 y GS $44^{13}$. Segundo, un ensayo sistemático a partir del concepto signa temporum, que tanto interesa a la hora de descubrir la manifestación de Dios en la historia, seguido de una formulación sintética sobre algunos desafíos teológicos para su interpretación. A modo de conclusión, enuncio algunas cuestiones abiertas sobre el giro soteriológico-pastoral del Vaticano II. Al preparar este texto en agosto de 2013, acaeció el primer aniversario de la muerte de Lucio Gera, quien fuera profesor de eclesiología y maestro en el ejercicio de la teología para varias generaciones argentinas; por este motivo, quiero dedicar este escrito a su memoria. La inclusión de sus aportes relativos al Concilio está, además, al servicio de una breve ejemplificación de lo que fue una parte del proceso de recepción conciliar en las iglesias locales del Cono Sur ${ }^{14}$.

\section{De los Signos Del Reino A los Signos de los tiempos}

1. El reino de Dios (LG 5)

\section{"La Iglesia pretende una sola cosa: que venga el reino de Dios" (GS 45)}

En respuesta al visibilismo eclesiológico vigente desde la Contrarreforma y ratificado por Mystici Corporis Christi en 1943, la constitución so-

12 Agradezco las valiosas preguntas y comentarios recibidos en este seminario para la revisión final de este texto, sobre todo aquellas/os referidos a las relaciones salvíficas entre Cristo y el Espíritu.

13 La elección de estos dos párrafos tiene como finalidad la articulación reflexiva de las dos constituciones implicadas y ofrecer un marco eclesiológico a la reflexión sobre la historia.

14 Sus textos serán citados como Escritos Teológico-Pastorales I-II a partir de la siguiente edición: V. R. Azcuy; C. M. Galli; M. GonzÁlez (Com. Teol. Ed.), Escritos Teológico-Pastorales de Lucio Gera I. Del Preconcilio a la Conferencia de Puebla (1956-1981) (Ágape/Facultad de Teología, Buenos Aires, 2006) y V. R. Azcuy; J. C. CaAmaño; C. M. Galli (Com. Teol. Ed.), Escritos Teológico-Pastorales de Lucio Gera II. De la Conferencia de Puebla a nuestros días (1982-2007) (Ágape/Facultad de Teología, Buenos Aires 2007). 
bre la Iglesia se sitúa en una perspectiva bíblica que intenta recuperar el lugar de la Iglesia en el horizonte del misterio salvífico de Dios revelado en la historia. La Iglesia del Padre, del Hijo y del Espíritu es la Iglesia de la Trinidad: "la Trinidad es el origen, la forma y la patria de la unidad eclesial, la fuente de donde esta nace, la imagen en donde esta se inspira y la meta hacia la que se dirige en el camino del tiempo"15. A partir de la Trinidad, la Iglesia se constituye como signo e instrumento histórico de salvación, aspecto que también se expresa con el concepto de mediadora, unida al Único Mediador (cf. LG 14a).

Como recuerda Lucio Gera, las dos categorías fundamentales de este primer capítulo de la constitución sobre la Iglesia son misterio e historia, aunque de la segunda no aparece ninguna explicación en el texto conciliar ni en las Relationes de la Comisión Teológica ${ }^{16}$. De acuerdo a las Relationes, "el vocablo misterio [...] designa la realidad divina trascendente y salvífica que se revela y manifiesta de algún modo sensible" ${ }^{17}$. De manera breve, cabe entender que el "misterio es la salvación" ${ }^{18}$, el designio salvífico de Dios que se vuelve a la humanidad y se revela a ella; de la Iglesia puede decirse que es misterio en cuanto comunidad de salvados que lo revela. La historia, por su parte, se concibe como un proceso de crecimiento: "la historia de la Iglesia universal es historia santa porque es participación, en el tiempo, del misterio de Dios; pero es historia porque es participación progresiva del misterio" ${ }^{19}$. Según Gera, la intención de exponer la materia según un orden histórico en el capítulo I, se manifiesta especialmente en el párrafo 5 -razón por la cual se retoma aquí-, construido conforme a la descripción sucesiva de las etapas de la Iglesia católica: su comienzo con la intervención de Cristo que la funda y la misión del Espíritu, en Pentecostés ${ }^{20}$.

15 B. Forte, La Iglesia de la Trinidad. Ensayo sobre el misterio de la Iglesia comunión y misión (Secretariado Trinitario, Salamanca 1996) 72.

16 Cf. L. Gera, "El misterio de la Iglesia", en Escritos Teológico-Pastorales I, 249-310, 249-250.258. Este texto fue editado originalmente en uno de los primeros comentarios a la Constitución Dogmática sobre la Iglesia en la región: R. FERRARA; L. Gera; otros, Lumen Gentium. Constitución Conciliar sobre la Iglesia (Editorial Guadalupe, Buenos Aires 1966) 45-106.

17 Schema Constitutionis de Ecclesia, 1964, Relationes, n1, 18. Citado por GERA.

18 L. Gera, "El misterio de la Iglesia", 251.

19 L. Gera, "El misterio de la Iglesia", 258.

20 Cf. L. Gera, "El misterio de la Iglesia”, 259-260. 
El número 5 de Lumen Gentium abre la segunda sección del capítulo I (cf. LG 5-7), que en conjunto asume algunas expresiones bíblicas, de carácter metafórico, como un modo de acercarse a la naturaleza mística de la Iglesia, sin la pretensión de una definición ${ }^{21}$. Este párrafo 5 se concentra en el tema del reino de Dios, explicitado en dos sentidos: uno cristológico, al afirmar que "el misterio de la santa Iglesia se manifiesta en su fundación" (5a) y otro eclesiológico, ya que "la Iglesia [...] recibe la misión de anunciar y establecer en todos los pueblos el Reino de Cristo y de Dios" (5b). El primer subpárrafo recorre los pasajes sinópticos que testimonian el anuncio del mensaje del Reino por parte de Cristo (cf. Mc 1, 15; Mt 4, 17, entre otros) y expresa que "este Reino se manifiesta a la humanidad en las palabras, en las obras y en la presencia de Cristo" (5a). Al concluir el subpárrafo, se enfatiza que: "ante todo, el Reino se manifiesta en la propia persona de Cristo, Hijo de Dios e Hijo del hombre, que vino a servir y a dar su vida en rescate por muchos (Mc 10, 45)" (5a). Según Philips, la persona de Cristo casi se identifica con el reino; Cristo es designado como al que viene para salvar y liberar ${ }^{22}$.

El subpárrafo 5 b está dedicado a explicar las relaciones entre la Iglesia y el Reino, que podrían entenderse en la línea de las relaciones Iglesia-Cristo ${ }^{23}$; este subpárrafo se orienta a distinguir entre la Iglesia en su realidad histórica y el Reino en su condición escatológica ${ }^{24}$. A su vez, un tema que está solo mencionado en este texto, la Iglesia es portadora del Reino por el don y la acción del Espíritu en ella: "Jesús, después de sufrir la muerte en cruz [...] apareció constituido Señor, Cristo y Sacerdote para siempre (cf. Hch 2, 36; Heb 5, 6; 7, 17-21) y derramó sobre sus discípulos el Espíritu prometido por el Padre (cf. Hch 2, 33)" (LG 5b). Es en la fuerza del Espíritu que la Iglesia "constituye el germen y

21 El tema se encontraba problematizado por entonces, como lo muestra GERA al citar la obra de Y. Congar, "Peut-on definir l'Église?", en Sainte Église. Études et aproches ecclésiologiques (Col. Unam Sanctam; Du Cerf, Paris 1963) 21-44. Texto traducido como: "¿Puede definirse la Iglesia? Destino y valor de cuatro nociones que se ofrecen a hacerlo", en Santa Iglesia (Editorial Estela, Barcelona 1965) 23-44.

22 Cf. G. Philips, La Iglesia y su misterio en el Concilio Vaticano II..., 121.

23 Sobre la fórmula del magisterio de Juan Pablo II, Iglesia como "sacramento del reino", en relación con la de Iglesia como "sacramento de Cristo" (LG 1), volveré más abajo.

24 En el ámbito católico, la obra pionera de R. SCHNACKENBURG, Reino y reinado de Dios (1959) fue iniciadora de una nueva visión teológica que no identificaba Iglesia y Reino, como fue frecuente en los medievales desde San Agustín. 
el comienzo de este Reino en la tierra" (5b); "la Iglesia, o el reino de Cristo presente ya en misterio, crece visiblemente en el mundo por el poder de Dios" (LG 3) 25 . De este modo, junto al orden temporal introducido en el párrafo 5 , se desarrolla una dinámica de crecimiento, que va de lo pequeño y lo germinal hacia una plenitud y madurez definitiva. Con palabras de Forte, se puede decir que: "la Iglesia no es el Reino de Dios en su forma completa; pero es su comienzo en la tierra, el germen que fecunda la historia, la levadura que crece hacia la realización prometida" 26 .

Ahora bien, si el párrafo 5 de Lumen Gentium introduce un acercamiento a la Iglesia como comienzo y manifestación del Reino de Dios en la historia, cabe preguntarse cuáles son los "signos" del Reino y "qué" manifiestan acerca de él ${ }^{27}$. El texto conciliar es claro: estos signos son la palabra, las obras y la presencia terrena de Cristo; será importante pensar, primero, su manifestación en la Iglesia, y luego, con Gaudium et spes, su presencia en la historia. Vamos por partes: la palabra involucra el momento del concepto, imagen o voz significante -el mensaje de Jesús sobre el Reino en tanto signo manifestativo del mismo- y el contenido o realidad significada, hablada y escuchada - la palabra como el mismo Reino, como en la parábola de la semilla de Mc 4, 14-. Por eso el primer subpárrafo afirma: "los que escuchan con fe y se unen al pequeño rebaño de Cristo (cf. Lc 12, 32) han acogido el Reino” (LG 5a); así se pone de relieve la interioridad mística del Reino, en cuanto realidad que nace de la voluntad de Dios y de la libre acogida humana -personal y comunitaria $-{ }^{28}$. Obras-milagros son otros signos salvíficos del Reino, que manifiestan el poder y la soberanía de Dios a través de Cristo. Finalmente, la persona de Cristo en la historia es la que manifiesta el Reino, el cual se hace visible en la cruz y en la redención ${ }^{29}$. Pero si se trata de explicar cómo actúa Dios en la historia, cómo se manifiesta su Reino, cabe des-

25 La cursiva es agregada.

26 B. FORTE, La Iglesia de la Trinidad..., 118.

27 Cf. L. Gera, "El misterio de la Iglesia", 282-291. Sigo aquí la reflexión teológica del autor.

28 Cf. L. Gera, "El misterio de la Iglesia”, 283.

29 Gera lo resume así: "La palabra comprende el signo manifestante y la realidad manifestada: el Reino se extiende mediante la predicación y es la Palabra interiormente recibida. Manifestación íntima de Dios trascendente al hombre, presencia de la Trinidad en la creatura: el Reino es equivalente al Misterio de Dios". L. GerA, "El misterio de la Iglesia", 284. 
tacar cuáles son las funciones del Espíritu en esta acción al servicio de la salvación de la humanidad: mientras que Cristo se reveló en signos y palabras, en su propia carne; el Espíritu se manifiesta en los signos mesiánicos y en los corazones de los creyentes enseñando el sentido de estos signos a la luz del acontecimiento pascual. En el texto conciliar, la acción del Espíritu es puesta en relación con Cristo muerto y resucitado: "después de sufrir su muerte de cruz y de resucitar [...] derramó su Espíritu” (5b). Se puede decir que las misiones de Cristo y del Espíritu se dan relevo una a otra y se entrelazan: Cristo inauguró su Iglesia y su Espíritu la anima, a través de todo tiempo y espacio, en su peregrinación histórica ${ }^{30}$.

Las relaciones de la Iglesia y el reino de Dios también pueden expresarse en clave misionera según las fórmulas de otros documentos: "la Iglesia pretende una sola cosa: que venga el reino de Dios y se instaure la salvación de todo el género humano" (GS 45); "la Iglesia ha nacido con la finalidad de propagar el reino de Dios" (AA 2) ${ }^{31}$. Esto significa que la Iglesia es "su signo vivo y visible, impregnado de la realidad ya iniciada, aunque no presente todavía del todo, el reino inaugurado por Cristo"32. Bruno Forte agrega que "hay una acción del Espíritu y una presencia de valores evangélicos más allá de los límites visibles de la Iglesia, que pueden ser considerados como momentos del Reino iniciado, que ha de venir plenamente"33. En palabras de Pié-Ninot, "la dimensión sacramental expresa adecuadamente la subordinación de la Iglesia al Reino" 34 . Al mismo tiempo, como veremos a continuación, la Iglesia sabe que el reino de Dios ya está presente misteriosamente en este mundo (cf. GS 39) y por ello está dispuesta a aprender de la historia y de la evolución humana (cf. GS 44).

30 Nos encontramos aquí en el horizonte de una "cristología pneumatológica" que tanto ha sido impulsada por Y. Congar y reclamada por J. Noemi para una teología de los signos de los tiempos latinoamericanos.

31 Cf. S. PiÉ-Ninot, Eclesiología, 229-230.

32 B. Forte, La Iglesia de la Trinidad, 119; la cursiva es agregada. Este aspecto encuentra un mayor desarrollo en el capítulo VII de Lumen Gentium dedicado a la escatología y al testimonio de los santos (cf. LG 50).

33 B. ForTe, La Iglesia de la Trinidad, 119. Este tema ha sido desarrollado en Redemptoris Missio 20.

34 S. Pié-Ninot, Eclesiología, 231. 
2. Ayuda que la Iglesia recibe del mundo actual (GS 44)

\section{[...] fuera de su estructura visible pueden encontrarse muchos elementos de santificación y de verdad [...] (LG 8b)}

Como background histórico de Gaudium et spes, Jan Grootaers recuerda que "la tradición propia de la Iglesia católica, después del fracaso de la cristiandad medieval, tomó al mundo como contraste valorativo; la Constitución marca un "giro» definitivo con respecto a ese pasado y es, por tanto, mucho más un "giro", y, consiguientemente, un nuevo punto de partida, que un «documento doctrinal» de la Iglesia docente" ${ }^{\text {" }}$. El capítulo IV de la primera parte de Gaudium et spes, sobre la función de la Iglesia en el mundo actual, "vuelve a tomar el título general de la misma Constitución De Ecclesia in mundo huius temporis, yuxtaponiéndole De munere (de la misión)" y examina "la razón profunda, consustancial, de la relación entre el pueblo de Dios y el género humano" ${ }^{36}$. Sobre él expresa Chenu que, quienes lo rechazaron, "eran refractarios a una concepción renacida y renovada del misterio de la Encarnación de Cristo en su dimensión total: recapitulación de la empresa humana y de la historia en la economía de la redención" ${ }^{37}$. La perspectiva cristológica recorre toda la constitución dando a la historia humana su perspectiva escatológica de plenitud" ${ }^{38}$ : "El Verbo de Dios, por quien todo fue hecho, se hizo carne de modo que, siendo Hombre perfecto, salvara a todos y recapi-

35 J. Grootaers, "Ruptura y presencia en "Gaudium et spes»", en Y. Congar; M. Peuchmaurd, La Iglesia en el mundo de hoy. Constitución pastoral Gaudium et spes, Tomo III: Reflexiones y perspectivas (Taurus, Madrid 1970) 53-80, 53.

36 M. D. Chenu, "La misión de la Iglesia en el mundo contemporáneo", en G. BaraúNA (dir.), La Iglesia en el mundo de hoy. Estudios y comentarios a la constitución "Gaudium et spes" del Concilio Vaticano II (Esquema XIII) (Studium Ediciones, Madrid 1967) 379-399. Este capítulo, que fue el resultado de una larga elaboración y que no figuraba en el proyecto inicial, fue ideado entre las últimas dos sesiones conciliares. Cf. R. TuCCI, "Introducción histórica y doctrinal a la Constitución Pastoral", en Y. Congar; M. Peuchmaurd, La Iglesia en el mundo de hoy. Constitución pastoral Gaudium et spes, Tomo II: Comentarios (Taurus, Madrid 1970) 37-155.

37 D.-M. Chenu, "La misión de la Iglesia en el mundo contemporáneo", 382. Seguiré, en este punto, el estudio de Gera al cumplirse los 30 años de Gaudium et spes: Lucio Gera, "La correlación entre la cristología y la antropología en la Constitución Pastoral Gaudium et spes", en Escritos Teológico-Pastorales II, 441-479.

38 Cf. GS 22: Cristo el Hombre Nuevo, al final de la sección I (12-22); GS 32: el Verbo encarnado y la solidaridad humana, al cierre de la sección II (23-32); GS 38: el perfeccionamiento de la actividad humana en el misterio pascual y GS 39: la tierra 
tulara todas las cosas" (GS 45b). La función de la Iglesia en la historia, como cuerpo de Cristo, es operar esta recapitulación por la fuerza del Espíritu, que anima a la familia humana a "hacer más humana su propia vida y a someter toda la tierra a este fin" (LG 38). Lo que la Iglesia puede aportar al género humano "deriva del hecho de que la Iglesia es el «sacramento universal de salvación"” (GS 45a). Cristo es "el fin de la historia humana, el punto en el que convergen los deseos de la historia y de la civilización, centro del género humano, gozo de todos los corazones y plenitud de sus aspiraciones" (45b), el alfa y la omega (cf. Ap 22, 12-13). Y la Iglesia es, en Cristo, como un sacramento (cf. LG 1).

Este capítulo, cuya ubicación en Gaudium et spes es significativa, desarrolla una enseñanza ya contenida en Lumen Gentium sobre las relaciones de "diálogo mutuo" entre la Iglesia y el mundo (GS 40a) que resulta clave en la comprensión de la constitución pastoral ${ }^{39}$. Retomando los fundamentos dogmáticos de la eclesiología, el capítulo se abre enunciando los ejes centrales de la exposición: la Iglesia de la Trinidad, fundada en el tiempo, está presente en medio de la ciudad terrena (40b), en conexión con LG 2-4 y AG 2-5; la Iglesia cree que puede contribuir a humanizar más la familia humana (GS 40c) -anticipando los párrafos 41-43- y está persuadida de que el mundo "puede ayudarla mucho y de muchas formas en la preparación del Evangelio" (40d), que anuncia el 44. Los párrafos que siguen explican la dinámica de esta mutua ayuda: de la Iglesia al mundo, a cada persona, a la sociedad y a la actividad humana (41-43) y del mundo a la Iglesia (44). La dimensión misionera de toda la Iglesia "tiene su origen en la misión del Hijo y la misión del Espíritu Santo según el plan de Dios Padre” (AG 2; cf. LG 17). "Esta misión continúa y desarrolla en el curso de la historia la misión del propio Cristo [...] impulsada por el Espíritu Santo” (AG 5); la razón última de esta actividad misionera es la voluntad salvífica universal expresada en 1Tim 2, 4-5: Dios quiere que todos se salven (cf. AG 7). Por eso, aunque "fuera de su estructura visible [de la Iglesia] pueden encontrarse elemen-

nueva y el nuevo cielo, como dos párrafos asociados al concluir la tercera sección (33-39); y GS 45: Cristo, alfa y omega.

39 La referencia a Pablo VI en el tema del diálogo es expresa: Ecclesiam suam III; aunque desde la tercera redacción del texto, a comienzos de 1964, se acentuaría la idea de solidaridad y una formulación de las relaciones Iglesia y mundo en perspectiva positiva y optimista. 
tos de santificación y de verdad" (LG 8b), el anuncio del Evangelio de salvación es un deber para todo el Pueblo de Dios (cf. 17; AG 1).

Con todo, lo realmente novedoso en el capítulo IV de la primera parte de GS es lo que se encuentra expresado en el último de sus párrafos sobre la ayuda que la Iglesia recibe del mundo actual: "de la misma manera que interesa al mundo reconocer a la Iglesia como realidad social y fermento de la historia, también la propia Iglesia sabe cuánto ha recibido de la historia y la evolución de la humanidad" (GS 44a). Esta última expresión, ita ipsa Ecclesia non ignorat, quantum ex humani generis historia et evolutione acceperit, representa las dos caras de una misma medalla: el reconocimiento positivo de la historia y la evolución del género humano y de lo mucho que la Iglesia ha recibido de ellas. Para explicar lo que la Iglesia recibe, se hace referencia específicamente al intercambio entre la Iglesia y las culturas con la finalidad de adaptar el Evangelio para que esté al alcance de la comprensión de todos (cf. LG 13b). Eclesialmente hablando, esta autocomprensión se sitúa en las antípodas de una Iglesia sociedad perfecta que está por encima de las (imperfectas) sociedades temporales; al reconocer lo que ha recibido de la historia y la evolución humana, la Iglesia sigue la actitud del mundo que la reconoce y plantea una relación recíproca con él. A continuación se sostiene que "la Iglesia, sobre todo en nuestro tiempo, [...] necesita, de modo peculiar, la ayuda de aquellos que viviendo en el mundo, conocen a fondo las diferentes instituciones y disciplinas y comprenden su mentalidad, sea que se trate de creyentes o no creyentes" $(44 b)^{40}$. En síntesis, se destaca la necesidad misionera que consiste en aprender "una predicación acomodada de la palabra revelada [...] como ley de toda evangelización” (44b).

Para comprender lo que está en juego en el Concilio y en particular en Gaudium et spes, sirven las palabras -ya anticipadas- de Yves Congar: "la Iglesia ha querido ser para el mundo, y para el mundo tal como es hoy"; en su actitud pastoral, ella está llamada a "escuchar al mundo y a aprender - por tanto a recibir-algo de él”; “en lenguaje más técnico, esto significa que la historia o la experiencia humana es para ella un «lugar teológico», una fuente de la que debe sacar elementos para su conoci-

40 El texto recuerda inmediatamente otro párrafo de Lumen Gentium en el cual se afirma que quienes buscan a Dios con sincero corazón e intentan en su vida, con la ayuda de Dios, hacer su voluntad según lo que les dice su conciencia, pueden alcanzar la salvación (cf. LG 16). 
miento y para la palabra que ha de pronunciar" ${ }^{\prime 1}$. Para Schickendantz, se trata de un paso importante para la renovada concepción de la Iglesia en la sociedad, para su credibilidad y una nueva forma de pensar; porque la historia emerge como "lugar teológico", una fuente a partir de la cual se puede hacer teología y profundizar el Evangelio ${ }^{42}$. Precisamente por esta razón es que, en el párrafo 44 de GS, se exhorta a discernir la historia:

"Corresponde a todo el Pueblo de Dios, especialmente a los pastores y teólogos, auscultar, discernir e interpretar, con la ayuda del Espíritu Santo, los diferentes lenguajes de nuestro tiempo y juzgarlos a la luz de la palabra divina, para que la Verdad revelada pueda ser percibida más completamente, comprendida mejor y expresada más adecuadamente"(44b).

El lenguaje y las expresiones de este fragmento se acercan mucho a los de otros párrafos en los cuales se hace referencia a "escrutar a fondo los signos de los tiempos e interpretarlos a la luz del Evangelio" (GS 4) y a "discernir en los acontecimientos, exigencias y deseos [...] cuáles son los signos verdaderos de la presencia o del designio de Dios" (11), si bien en el párrafo 44 no aparece explícitamente la fórmula signa temporum-por el debate que esta suscitó-. Una comparación entre los tres párrafos, no obstante, deja en claro la novedad de este último en lo relativo a la positividad y la densidad teológica de la historia: "el Concilio le reconoce un valor propio, que no es reducible a su papel de medio para la realización de los bienes sobrenaturales" ${ }^{43}$. Lo temporal, que ha sido reconocido como mucho más histórico, cósmico y social, no está subordinado a lo espiritual, sino que está destinado a realizarse plenamente como mundo en la perspectiva del Reino de Dios. La misión de la Iglesia en relación con los signos de los tiempos se expresa con los verbos "escrutar" (GS 4a), "interpretar" (4a; 44b), "discernir" (4e; 11a; 44b), “juzgar” (11b), "auscultar" (44b). En este envío, el Pueblo de Dios "cree que es guiado por el Espíritu del Señor" (11) y cuenta con su ayuda (cf. 44b), para responder a los interrogantes humanos y a las aspiraciones más profundas, muchas veces dramáticas del presente y para que la Verdad revelada sea mejor percibida, comprendida y expresada (cf. 4a; 44b).

41 Y. Congar, "Iglesia y mundo en la perspectiva del Vaticano II", en Y. Congar; M. Peuchmaurd, La Iglesia en el mundo de hoy III, 17-45, $33.34 \mathrm{~s}$.

42 Cf. C. Schickendantz, "Una elipse con dos focos...", 71-73. El autor asume los aportes de Turbanti y Ruggieri.

43 Y. CONGAR, "Iglesia y mundo en la perspectiva del Vaticano II", 36. 
Recapitulando, la Iglesia está al servicio del Reino de Dios y como sacramento de este reino en la historia, está llamada a anunciar el Evangelio de la salvación a toda la humanidad. A su vez, mientras la Iglesia peregrina en la historia, por el camino de la humildad y la pobreza (cf. LG 8c; AG 5b), aprende de la historia y discierne en sus acontecimientos los signos de Dios (cf. GS 44; 11). ¿Cómo se manifiesta Dios en la historia? Por medio de Cristo y por la fuerza de su Espíritu, en la Iglesia y más allá de su estructura visible; en la Palabra y en la evolución de la historia humana, a través de los signos de los tiempos y en su discernimiento. La Iglesia peregrina en la historia vive "en el punto de cruce entre el Evangelio y la vida de cada día" ${ }^{44}$; ella no es solo germen y principio del reino de Dios, sino que está llamada a convertirse al reino. Aprender de la historia significa, en definitiva, la conversión de la Iglesia al reino, según la expresión de Ignacio Ellacuría, es decir, no ceder a la tentación de mundanizarse y estar dispuesta a reconocer cuándo y cómo lo ha hecho $^{45}$. Aceptar el reto de conversión que viene de la historia representa, para todos los cristianos, el desafío de interpretar los acontecimientos y las crisis que surgen de los asuntos humanos y sociales e introducirse en conversaciones y debates que cuestionan la fe y piden una respuesta ${ }^{46}$.

\section{De los SIGNOS DE LOS TIEMPOS A SU DISCERNIMIENTO TEOLÓGICO}

1. La expresión signa temporum y su significado en el Vaticano II

Que el pueblo de Dios extienda por todo el mundo el Reino de Cristo, Señor y escrutador de los siglos

(AG 1c)

El significado de la noción signos de los tiempos se fue clarificando a partir de su uso en el magisterio por parte de Juan XXIII, Pablo VI y los documentos del Concilio Vaticano II, sobre todo de la Constitución

44 Comisión Teológica Internacional, La teología hoy, № 52.

45 Cf. I. Ellacuría, Conversión de la Iglesia al Reino de Dios. Para anunciarlo y realizarlo en la historia (Sal Terrae, Santander 1984).

46 Cf. Comisión Teológica Internacional, La teología hoy, № 52 . Quizás aquí se hace visible, como indicaré más abajo, que la lectura de los signos de los tiempos está en relación con el testimonio cristiano. 
pastoral Gaudium et spes ${ }^{47}$. La historia redaccional de la expresión signa temporum está estrechamente ligada a las discusiones sobre la expositio introductiva -propuesta por G. Philips entre marzo y abril de 1965- y al método inductivo; que la misma solo haya quedado en el párrafo 4 de la constitución, pone en evidencia el tenor de la discusión. Para salvar su inclusión, en la presentación final en el aula conciliar, McGrath -en función de relator- se ve obligado a aclarar que su uso no era en un "sentido técnico, sino general", en un sentido empírico, en referencia a hechos importantes que caracterizan una época ${ }^{48}$.

Con respecto al significado de la expresión, vale la pena recordar algunas formulaciones de M. D. Chenu a poco de concluir el Concilio: "los teólogos de este tiempo encontrarán una gozosa complacencia en captar la luz deslumbrante que la expresión signos de los tiempos introduce en la inteligencia de la economía cristiana, para detectar al hilo de la historia la presencia de la Palabra de Dios" ${ }^{29}$. La expresión signa temporum pone a la historia en relación con Dios: tempus signum et vox est, decía la primera redacción del texto conciliar, es decir, toma de conciencia que hace que el hecho se convierta en $\operatorname{signo}^{50}$. En cuanto categoría teológica, Chenu señala que:

"[...] signa temporum es algo que se sitúa en esa categoría de signos que emanan de las realidades de la historia. Este carácter específico los diferencia de los «naturales», que provienen de la naturaleza de las cosas $[\ldots]$ y de los "convencionales», que proceden de una inicia-

47 La expresión se encuentra en la Bula de Convocatoria al Concilio, Const. apost. Humanae salutis del 25 de diciembre de 1961 (AAS 54 [1962] 5-13). Para una historia detallada de la expresión y sus avatares durante las discusiones conciliares, puede verse C. Schickendantz, "Una elipse con dos focos...", 67ss.

48 Cf. Las críticas al uso de la expresión en N. TANNER, "La Iglesia en el mundo (Ecclesia ad extra)", en G. Alberigo (dir.), Historia del Concilio Vaticano II. Volumen IV: La Iglesia como comunión. El tercer periodo y la tercera intercesión (Sígueme/Peeters, Salamanca/Leuven 2007) 251-356, 254 ss.

49 M. D. Chenu, "Los signos de los tiempos", en: Y. Congar; M. Peuchmaurd, La Iglesia en el mundo de hoy II, 253-278, 253. Paul Valadier cuestionó el entusiasmo de esta afirmación de Chenu y enfatizó que "Dios no se presenta fuera de la libertad humana, y en este sentido, solamente el hombre es lugar de la revelación de Dios [...]. No buscaremos signos de Dios en la historia, pero intentaremos discernir en los acontecimientos de nuestra actualidad a qué solicita la libertad divina a nuestra libertad humana”. P. VAladier, “¿Signos de los tiempos, signos de Dios?”, Criterio 1646 (1972) 328-333, 332.333.

50 Cf. M. D. Chenu, "Los signos de los tiempos" [original de 1967], 261. 
tiva humana (gestos, lenguaje, cifras); se inscriben en los hechos, en los acontecimientos, que poseen en virtud de su contextura y de su contexto humano, una «significación» que sobrepasa y envuelve su materialidad. Todo lo cual nos puede hacer prever que, en el dominio de la teología, los signos de los tiempos no llegarán a ver registrado su papel funcional más que en la medida que el cristianismo se conciba como una «economía» en el tiempo, y no, ante todo, como un conjunto de conceptos dentro de una doctrina temporal" ${ }^{51}$.

Para Chenu, distinguiéndose de los signos naturales y convencionales, los signos de los tiempos son hechos o acontecimientos, pero no cualesquiera, sino aquellos que poseen una particular significatividad que sobrepasa su materialidad. Con ellos se relaciona la propuesta del método inductivo en Gaudium et spes y, unida a él, la búsqueda de una teología "concreta e histórica, centrada en la historia de la salvación" -según la expresión de Pablo VI en la audiencia del 17 de octubre de 1963-. En el Documento de Base que sirvió en la preparación de la II Conferencia de Medellín, dos de las orientaciones retomaban estas líneas conciliares: la adopción del método pastoral y la preocupación por una pastoral que respondiera a los signos de los tiempos ${ }^{52}$. En la realización de la II Conferencia de Medellín ${ }^{53}$ se trató de discernir, a la luz del signo distintivo de aquellos tiempos, el subdesarrollo, la aspiración a la justicia y los caminos del Espíritu para lograrla, es decir, se necesitaba una sabiduría hecha de experiencia histórica, una prudencia política o sabiduría pastoral que fuera capaz de un juicio práctico sobre las decisiones oportunas ${ }^{54}$. En definitiva, la noción signos de los tiempos requería una actitud pastoral, de apertura a la realidad histórica, ni puramente doctrinal ni solamente empírica ${ }^{55}$. Una disposición a la interpelación del Espíritu en la historia.

51 M. D. Chenu, "Los signos de los tiempos" [1967], 259.

52 Cf. V. R. Azcuy, "La pobreza de la Iglesia y los signos de los tiempos. Medellín como recepción inacabada del Vaticano II", en V. R. AzcuY; C. Schickendantz; E. Silva, Teología de los signos de los tiempos..., 89-126, 107.

53 Para ello ver V. R. AzcuY, "El discernimiento teológico-pastoral de los signos de los tiempos en Medellín”, en Teología 107 (2012) 125-150; V. R. Azcuy, "La pobreza de la Iglesia y los signos de los tiempos...”, 89-126.

54 Cf. L. Gera, “Teología de los procesos históricos y de la vida de las personas”, en Escritos Teológico-Pastorales II, 869-890, 888s.

55 Cf. L. Gera, "La Iglesia y el mundo", en Escritos Teológico-Pastorales I, 311-318. 
2. Ensayo de conceptualización sobre los signa temporum

Siguiendo el sentido abierto por las enseñanzas del Concilio Vaticano II, me interesa ahora ensayar una formulación conceptual algo más elabora$\mathrm{da}$, que asume distintos aportes teológicos del posconcilio. Este intento es fruto de lecturas y conversaciones en el marco del programa Teología de los signos de los tiempos latinoamericanos del Centro Teológico Manuel Larraín ${ }^{56}$. Los signos de los tiempos son acontecimientos significativos que marcan la historia por su generalización y frecuencia, desencadenan conciencia y conmoción, esperanza y orientación en una época, creando un consenso o asentimiento básico universal -entre creyentes y no creyentes- frente a las necesidades y las aspiraciones que caracterizan la historia humana ${ }^{57}$. Son fenómenos históricos extendidos en todo un ciclo de vida colectiva, que captan progresivamente una generación, un pueblo, una cultura o civilización, y adquieren el valor de signos históricos porque impactan e interpelan a la libertad humana dando una señal hacia formas de existencia más justas y más dignas. Los signos de los tiempos no son hechos aislados, sino generalizados; no son signos naturales o convencionales, sino signos históricos ${ }^{58}$. Personalmente, además, me inclino a pensar que los signos de los tiempos no son historias personales, por más significativas que estas sean, sino acontecimientos o procesos históricos que impactan en las vidas humanas de muchos. En mi visión, esto no significa que ellas queden excluidas de una teología de los signos de los tiempos, por cuanto que pueden ser consideradas en la perspectiva de la respuesta a estos ${ }^{59}$.

56 Una primera síntesis conceptual fue publicada en V. R. AzcuY, “El Espíritu y los signos de estos tiempos. Legado, vigencia y porvenir de un discernimiento teológico", en Concilium 342 (2011) 601-212, 602s.

57 Cf. R. Fisichella, “Los signos de los tiempos en el contexto contemporáneo”, en Medellín 65 (1991) 55-71; R. Fisichella, voz "Signos de los tiempos", en R. FISichella; R. Latourelle (eds.), Diccionario de Teología Fundamental (San Pablo, Madrid 1992) 1360-1368; G. Gennari, voz "Signos de los tiempos", en S. DE FIORES; T. GOFFI (eds.), Nuevo Diccionario de Espiritualidad (San Pablo, Madrid 1991) 1758-1779.

58 Cf. M. D. Chenu, "Los signos de los tiempos" [1965], en C. Schickendantz (ed.), A 40 años del Concilio Vaticano II. Lecturas e interpretaciones (EDUCC, Córdoba 2005) 83-101, 90.

59 Otros sostienen, en cambio, que los testigos significativos pueden considerarse también como signos de los tiempos. La discusión permanece abierta en este punto, para proseguir la reflexión. 
El carácter significativo de los signos de los tiempos no está sobreañadido a causa de una ideología, un subjetivismo o moralismo de quienes los leen, sino que está encarnado y se manifiesta de forma clara en la realidad histórica. Su significatividad está presente en la densidad histórica de los acontecimientos y en la apelación a la conciencia y al cambio que se dirige a la libertad de los diversos actores históricos. Algunos criterios para identificar/los o distinguir/los pueden ser: su tipicidad o modo característico de marcar la época, sus indicios de tiempos mejores, el consenso colectivo que suscitan, su profundidad e irreversibilidad ${ }^{60}$. En el ámbito de su identificación, la teología necesita aprender y dejarse aportar por la mediación de las ciencias humanas y sociales y eventualmente por medio del saber cultural popular ${ }^{61}$, tanto para reconocer como para describir e interpretar los fenómenos característicos de una época o generación.

Ahora bien, los signos de los tiempos como acontecimientos significativos exigen un desciframiento, una interpretación ${ }^{62}$. Hablar de ellos supone la existencia de un sujeto intérprete, que en nuestro caso es la comunidad de fe, un sujeto creyente en diálogo con su época, porque los hechos se transforman en signos por la $\mathrm{fe}^{63}$. El intérprete también puede ser un cuerpo colegiado, como el de los obispos en las Conferencias Generales de América Latina y el Caribe, o un sujeto teológico o interdisciplinario, con sentido académico, pastoral y/o espiritual. Siguiendo la perspectiva conciliar parece indispensable que este sujeto sea colectivo, para hacer el ejercicio de disponerse a aprender del tiempo presente y asumir la tarea de discernir sus signos (cf. GS 4, 11). Se plantea, así, el desafío de una interpretación creyente de los acontecimientos históricos, una interpretación más global y universal del mensaje salvífico a partir de las marcas de la época; se intenta desentrañar en los signos del tiempo su sentido latente y oculto más allá de su objetividad real, su fuerza apelativa para la libertad humana y para la misión evangelizadora de la Iglesia. Como todo discernimiento, la interpretación de los signos de los tiempos no está exenta de dificultades y tentaciones; entre ellas, la de

60 Cf. M. A. Fiorito; D. Gil, "Signos de los tiempos, signos de Dios. Apuntes para una teología, una espiritualidad y una pastoral de los signos de los tiempos", en Stromata 32 (1976) 3-95; X. QuinZÁ, "Leer los signos de los tiempos”, en Razón y fe 212 (1985) 377-386, 378.

61 Cf. M. Fiorito; D. Gil, "Signos de los tiempos, signos de Dios...”, 60ss.

62 Cf. P. Valadier, “¿Signos de los tiempos, signos de Dios?”, 330.

63 Cf. J. Comblin, “Signos de los tiempos”, en Concilium 312 (2005) 87-100. 
"anexionar a Dios a nuestros propios conflictos y a nuestras posiciones personales, con la consecuencia de declinar fácilmente responsabilidades propias en el secreto del plan divino y de no asumir los riesgos inherentes a la decisión humana" ${ }^{34}$. En este sentido, la dimensión de consenso generalizado frente a determinados hechos y el sensus fidelium del Pueblo de Dios en una época determinada pueden ayudar en la interpretación ${ }^{65}$.

Como señala Gaudium et spes, el discernimiento de los acontecimientos, exigencias y deseos del tiempo presente es una tarea de todo el Pueblo de Dios bajo la guía del Espíritu (cf. GS 11; 44). El servicio de la teología ayuda a discernir los signos de Dios en los signos de los tiempos, sabiendo que la vida de Cristo abre la inteligencia de toda la historia y constituye el criterio fundamental de la fe (cf. Mt 16, 3; Lc 12, 54-56) ${ }^{66}$. Para los cristianos, el criterio por excelencia de lo que se entiende por Dios, por el ser humano y por el mundo es la persona de Jesucristo y el advenimiento de su reino. Jesucristo, el Verbo hecho carne, es el universal-concreto, un singular-absoluto, a cuya luz se puede discernir la topología plural-histórica de los signos de los tiempos ${ }^{67}$. El Espíritu ilumina los ojos de la fe para percibir a Cristo y descifrarlo en los tiempos ${ }^{68}$, para comprender las apelaciones del Dios de Jesucristo a la libertad humana en medio de los sucesos y las voces de la historia. Desde el punto de vista de la evangelización, la interpretación de los signos también plantea la

64 A. Antón, La Iglesia de Cristo, 780.

65 Corresponde a una teología de los signos de los tiempos la difícil tarea de esclarecer una criteriología que permita distinguir cuáles son estos signos de la presencia salvífica de Dios o de su negación. Al respecto, se puede ver Eduardo Silva, "Criterios de discernimiento para una teología de los signos de los tiempos latinoamericanos", en V. R. Azcuy; C. Schickendantz; E. Silva, Teología de los signos de los tiempos..., 173-208.

66 Cf. P. Valadier, “¿Signos de los tiempos, signos de Dios?”, 332. Se omite aquí intencionalmente la expresión "Cristo, el Signo de los tiempos", dado que ella obliga a una analogía muy extensa en el uso del concepto.

${ }^{67}$ Cf. H. J. SANDER, “Die singuläre Geschichtshandeln Gottes...”, 142. También en este caso omito la aplicación de la noción "signo de los tiempos" a Cristo y tomo su idea sobre lo singular y lo plural para plantear la relación entre Cristo y los signos del tiempo.

68 Galli afirma que Jesucristo hace inteligible a los ojos de fe los signos de Dios, pero prefiero -con Balthasar- la formulación pneumatológica en este punto. Cf. C. M. GALLI, "Aportes para la interpretación teológica de los signos de los tiempos", en SoCIEDAD Argentina de TeOlogía (ed.), La crisis argentina: ensayos de interpretación y discernimiento a la luz de la fe (San Benito, Buenos Aires 2004) 247-252, 250. 
exigencia de establecer una relación constitutiva entre el anuncio del Evangelio y la condición histórica de los/as destinatarios/as, que sea capaz de integrar el desafío del respeto a su alteridad y el mandato de hacer audible el Evangelio ${ }^{69}$. Al decir de Chenu, se trata de escuchar la Palabra al hilo de la historia, es decir, escucharla como Palabra dicha a la humanidad y acogida por ella -si no es rechazada- para la salvación universal. En definitiva, como apunta José Comblin, el objetivo al discernir los signos de los tiempos es "saber qué hacer en el momento actual para que se realicen los tiempos anunciados por Jesús"70, es decir, aceptar el desafío de la conversión al reino en sentido personal, comunitario y pastoral.

\section{La tarea teológica del discernimiento de la historia}

\section{"El Pueblo de Dios procura discernir en los acontecimientos, exigencias y deseos que comparte con sus contemporáneos, cuáles son los signos verdaderos de su presencia" (GS 11)}

La tarea de una teología de los signos de estos tiempos, para Juan Noemi, requiere afrontar una primera dificultad: no se trata solo de asumir el desafío de la historia como lugar teológico -según Gaudium et spes- sino de superar, a la vez, la insuficiencia metodológica consistente en yuxtaponer el diagnóstico empírico sobre el presente teológico ${ }^{71}$. Una lectura teológica de los signos de los tiempos presupone que Dios interviene y actúa en la historia, es decir, no disocia la historia de salvación de la historia universal, sino que busca lo teológico en lo histórico. La teología de los signos de los tiempos es, de este modo, una teología de la historia, una interpretatio temporis pues la acción de Dios acontece en la historia y la teología procura descubrir la acción/pasión del Dios de Jesucristo por medio de su Espíritu ${ }^{72}$. La teología asume, de este modo, la función hermenéutica de descubrir el sentido divino oculto en los

69 Cf. Ch. Theobald, “Lire les signes de temps”, en Études 406 (2007) 197-212.

70 J. Comblin, "Signos de los tiempos", 532.

71 Cf. J. Noemi, "En búsqueda de una teología de los «signos de los tiempos»", en Fernando Berríos; Jorge Costadoat; Diego García (eds.), Signos de estos tiempos. Interpretación teológica de nuestra época (Ediciones Universidad Alberto Hurtado, Santiago de Chile 2008) 83-98, 85.

72 Cf. P. Hünermann, "La acción de Dios en la historia. Teología como interpretatio temporis”, en J. O. Beozzo; P. Hünermann; C. Schickendantz, Nuevas pobrezas e identidades emergentes. Signos de los tiempos en América Latina (EDUCC, Córdoba 2006) 17-59. 
acontecimientos históricos considerados signos de los tiempos, busca desentrañar ese sentido entre otros sentidos y en los sentidos que la misma realidad tiene, porque toda realidad, cualquier realidad humana, es portadora de sentido divino, tiene sentido en el camino del varón y la mujer hacia Dios. Del mismo modo determinados signos, en lugar de dar testimonio de Dios, son un obstáculo para su acción y deben ser denunciados para no apartarnos del querer de Dios para la vida humana, por constituir una negación del plan de salvación ${ }^{73}$.

En la lectura interpretativa de los signos bajo la guía del Espíritu -como es el intento del Centro Teológico Manuel Larraín desde su constitución en 2005-, el sujeto y el objeto de la acción reflexiva son y quieren ser plurales. La tarea de descubrir la significación teológica de los acontecimientos se enriquece cuando es asumida por todos los bautizados/as y es fruto del diálogo entre disciplinas para auscultar con mayor rigurosidad las diversas facetas de los fenómenos históricos. Laicos y pastores, mujeres y varones, teólogos "de a pie" y profesionales, reciben la sabiduría del Espíritu para orientar cristianamente la vida. Con respecto al objeto, se puede hablar de una multiplicidad de signos; una teología basada en esta pluralidad de signos necesita imaginar y elaborar sus propias cartografías, ya que la pregunta por los signos de estos tiempos resulta difícil de abarcar, impone prioridades, opciones y etapas, localizaciones concretas. Una ayuda teórica para despejar el camino es, sin duda, el desarrollo de H. J. Sander sobre la "topología plural” de los signos de los tiempos, los distintos-lugares de la una manifestación salvífica de Dios en la historia ${ }^{74}$. Los signos de los tiempos señalan una exigencia de pluralidad en el lugar de Dios en la historia que pueda conjugar los muchos signos del tiempo y la una historia de la salvación. Se vuelve necesario -como señala Noemi- profundizar "la fe en la presencia y guía del Espíritu en la historia como supuesto fundamental de una teología de la historia que, sin embargo, apenas se ha articulado suficientemente al menos en el Occidente cristiano"75. En la práctica, la universalidad de la topología plural de los signos invita a estudios locales, necesariamente parciales; una teología de los signos de los tiempos latinoamericanos manifiesta la dimensión espacial, del lugar o los lugares en que sitúa su

73 Cf. E. Silva, “Criterios de discernimiento para una teología...”, 186ss.

74 Cf. H. J. SANDER, "Die singuläre Geschichtshandeln Gottes...”, 134-147.

75 J. Noemi, “En la búsqueda de una teología de los «signos de los tiempos»”, 93. 
lectura y busca además acotarse a fenómenos concretos. La teología de los signos de estos tiempos pide, de este modo, no solo un discernimiento de las marcas de una época, sino también una necesaria ubicación topológica y una interpretación situada, mostrando así su parentesco con las teologías contextuales. Acuerdo con Eduardo Silva cuando señala que la teología latinoamericana y contextual evidencia su carácter provisorio, pero al mismo tiempo manifiesta la terquedad de una teología que no está dispuesta a dar la espalda a la realidad y que, en su provisionalidad, funda el vigor de su vigencia ${ }^{76}$.

Sintetizando, la expresión signa temporum-como tantas otras fórmulas nuevas que solo entraron una vez o tal vez ninguna en los documentos finales del Concilio Vaticano II- representa un cambio de paradigma en las relaciones de la Iglesia con el mundo actual. La Iglesia que peregrina en la historia, siendo sacramento universal de salvación, quiere aprender de la evolución de la historia humana. Siguiendo al Señor y escrutador de los tiempos, ella se siente impulsada a escrutar los signos de los tiempos con la guía del Espíritu; en esta tarea, el Pueblo de Dios, sobre todo los obispos y los/as teólogos/as -en diálogo con todo el pueblo de Dios y las diversas culturas-, reciben el mandato de discernir la historia para que la Palabra sea mejor percibida, comprendida y expresada.

\section{A MODO DE CONCLUSIÓN}

"Corresponde a la Iglesia el deber permanente de escrutar los signos de los tiempos e interpretarlos a la luz del Evangelio" (GS 4)

\section{"El Concilio Vaticano II ha querido ser un Concilio pastoral"}

La recepción del Concilio Vaticano II implica un proceso de aceptación de sus enseñanzas y al mismo tiempo una llamada de renovación para poner en práctica lo explicitado en ellas del anuncio evangélico. Como explica Lucio Gera, no se trata solo de repetir citas, sino de reproducir las actitudes conciliares, y una de ellas, tal vez la más definitiva, universal

76 Cf. Eduardo Silva, "Una teología de los signos de los tiempos latinoamericanos. Validez, límites y porvenir de una hermenéutica teológica del Concilio", en Teología y Vida L (2009) 41-58, 57.

77 L. Gera, "La Iglesia y el mundo", 311. 
y englobante, ha sido la preocupación pastoral ${ }^{78}$. Esta actitud pastoral representa una clave fundamental para comprender la acción salvífica de Dios en la historia y para orientar la misión eclesial evangelizadora como servicio a la humanidad. El giro salvífico del Concilio Vaticano II parece estar, precisamente, en esta actitud de diálogo, servicio y solidaridad con la historia humana. Ella lleva a la Iglesia a entenderse en su acontecer histórico, "en el punto de cruce entre el Evangelio y la vida de cada día, que es también la línea fronteriza entre el pasado y el futuro, puesto que la historia avanza"79. Es en el ámbito de su misión, que la Iglesia encuentra la razón de su identidad: escuchar a Dios en el servicio a la humanidad, discernir su acción en el presente y convertirse constantemente al reino de Dios como modo de caminar hacia él. En este sentido, Christoph Théobald habla de una "doble escucha" siguiendo la inspiración de Gaudium et spes: "de la Palabra de Dios y de «lo que es verdaderamente humano en la sociedad» (GS 1)" ${ }^{80}$. Quizás en esto se descubre una pista para escrutar, a la vez, los signos de los tiempos y el testimonio de los creyentes que responden a ellos.

78 L. GerA, "La Iglesia y el mundo", 311. Ya en diciembre de 1962, Chenu señalaba que "el aspecto pastoral se ha convertido en el criterio fundamental utilizado en la formulación y en la presentación de la verdad". G. Alberigo, "La transición hacia una nueva era", en: Historia del Concilio Vaticano II. Volumen V: Un Concilio de transición. El cuarto período y la conclusión del Concilio (Sígueme/Peeters, Salamanca/Leuven 2008) 509-569, 516.

79 Comisión Teológica Internacional, La teología hoy, № 52.

80 Ch. Théobald, "El Concilio Vaticano II frente a lo desconocido. La aventura de un discernimiento colegiado de los «signos de los tiempos", Concilium 346 (2012) 373-382, 378. 